\title{
CRM Systems for Small Businesses: The Role in the Digital Transformation and New Opportunities During COVID-19
}

\author{
Lilia Matraeva, Ekaterina Vasiutina, Nataliya Korolkova
}

Russian State Social University, V.Pika, 4, Moscow, Russia

\begin{abstract}
The growing trend of focusing on customer focus, combined with business informatization, is becoming a critical aspect of the competitiveness of modern enterprises, regardless of their size. The introduction of new technologies by small enterprises allows them to develop and grow rapidly. This article is aimed at determining the readiness to use CRM systems in small businesses, as well as identifying the factors that small companies take into account when deciding on the implementation of the CRM. In the article, a holistic view of the use of the needs in the development of the CRM systems for small businesses is presented.
\end{abstract}

Keywords - CRM system, small enterprises, digitalization of small businesses, questionnaires, survey results.

\section{Introduction}

One important feature can distinguish a company from a huge number of competitors - the ability to work well with customers, to serve them efficiently.

DOI: 10.18421/TEM111-16

https://doi.org/10.18421/TEM111-16

Corresponding author: Matraeva Lilia,

Russian State Social University, V.Pika, 4, Moscow, Russia Email: lilia.matraeva@gmail.com

Received: 19 August 2021.

Revised: 10 January 2022.

Accepted: 18 January 2022.

Published: 28 February 2022.

(c))BY-NC-ND (C) 2022 Lilia Matraeva, Ekaterina Vasiutina \& Nataliya Korolkova; published by UIKTEN. This work is licensed under the Creative Commons AttributionNonCommercial-NoDerivs 4.0 License.

The article is published with Open Access at www.temjournal.com
It was for these purposes that the CRM systems (Customer Relationship Management) appeared on the market in the 80 s of the XX century. Even at that time, companies identified a priority group of customers who were given special attention. Customer relationship management systems became widely known in the early 1990s in the Western community. The rapid development of information technology and computing technology made it possible to work with large databases. At the same time, it became possible to process and analyze large amounts of information for making strategic decisions. Thus, the first prototypes of the CRM systems appeared.

According to analytics from Gartner, the volume of global CRM in 2018 amounted to 48.2 billion USD [1]. This is a huge jump from the $\$ 16.5$ billion in revenue generated by this market in 2010 [2]. At the same time, analysts are confident that these data indicate only the beginning of the recovery: according to forecasts, it will grow by an average of $14.2 \%$ in the period from 2020 to 2027 [3].

However, the development of the CRM market is not uniform. If in the West such systems began to develop actively in the $80-90$ s of the 20th century, then in our country and in the countries of the former COMECON bloc, due to the crisis of the $90 \mathrm{~s}$, this process began much later. It may also be related to cyclical changes and determinants of long-term economic dynamics in terms of the impact on the development of business cycles in these countries [4]. But the situation has changed significantly over the past 10 years. The CRM systems have become interested not only in large companies and banks, as it was in the beginning, but also in representatives of small businesses.

Thus, the purpose of the study is to determine the readiness for the use of the CRM systems in small businesses, as well as to identify the factors that small companies take into account when making a decision on the implementation of the CRM. 


\section{Theoretical Background}

As already noted, the beginning of the formation of the CRM is considered to be the 80 s of the XX century. CRM systems were considered as part of the service quality models. At the same time, the main emphasis was placed on the technical component: the collection of information about customers, the allocation of priority groups in a partially automated mode [5]. At that time, the abbreviation CRM did not yet exist. The predecessors were Database Marketing - a simple accumulation and fragmentary analysis of customer information, and then, since 1986, Contact Management Software (CMS) - software for managing customer contacts, representing systematized customer information in the form of an electronic client file.

At the next stage of development, the Sales Force Automation (SFA) systems appear, which move from contact management to sales automation. The combination of these two functions leads to the formation of a variety of terms and systems with the dominance of certain functional modules, including the Enterprise Customer Management (ECM) and the Customer Information System (CIS). However, the term "CRM" has been fixed in practice, which has been stable since 1995 [6].

By the end of the 1990s, RM systems began to undergo a qualitative transformation, which became a prerequisite for the subsequent systemic transformation of the concept of customer relationship management [7]. And although the CRM systems were still perceived as software complexes, but now the main competitive advantage was the use of information technologies to meet the needs of the client on the client's terms: to constantly meet the changing (and not static) needs and desires of customers; the development of not only ways to provide all the necessary information for customers, but also new ways of packaging information to make it more valuable for customers; the formation of "a portfolio of potential experiences", etc.

It is at this stage that the CRM begins to be implemented with a new approach - software as a service (SaaS). It is interesting to note that this decision was formalized specifically for small businesses and only then received distribution among large businesses.

The turning point is the beginning of the $2000 \mathrm{~s}$, when a number of works on the CRM in a broader sense are published. Thus Gordon, in his research, for the first time drew attention to the fact that high indicators of the effectiveness of the CRM implementation were observed in those companies that develop their CRM plans from the point of view of strategic opportunities. This contributes to the fact that the company responds more flexibly to a wide range of market and industry changes, without correcting the main vector of the strategic plan [8].

And if the improvement of the company's efficiency and competitiveness, according to the strategic plan, is built in four projections: technologies, people, knowledge, processes, then more and more advanced companies are combining their capabilities to use the CRM not only in the field of technology, but also on the development and funding of organizational capabilities in other areas. With this approach, the potential and success of using the CRM system solutions is based on a balanced approach to the development and implementation of strategic opportunities.

Thus, according to Gordon, the CRM system, considered only as a means to increase sales in the short term, although it is a means of effective interaction with customers, however, does not use its full potential for the strategic development of companies and such a narrow approach should be overcome.

Peel adheres to a similar point of view. In his book, the author emphasizes that in many organizations, especially large ones, the implementation of the CRM strategies begins and ends with the introduction of a technology that is excessively focused on internal processes, and not on communication with customers and interaction with them [9]. Increasingly, customer interaction management technologies are fragmented and tactical in nature. Despite the fact that a wide range of tactical solutions is available to companies with the introduction of the CRM, the realization of the system's potential is possible only if we take into account the more diverse strategic consequences of convergence in the direction of the customer relationship management strategy (and the associated customer interaction management architecture) for the enterprise.

There is a shift in priorities from technologies when interacting with customers to managing communications with customers. Initially, there is an increased attention to the CRM as a marketing concept [10], [11], [12], [13]. That is, the presence of feedback and the creation of a dynamic system of interaction with customers is emphasized. The main components of customer relationship management in the implementation of a CRM strategy are:

- emphasis on quality, and thanks to the CRM, it focuses not so much on the quality of the product or service, but on the quality of service.

- the degree of customer satisfaction, with the ability to manage customer service, in case there are gaps between expectations and results after the purchase process.

- investing in people. Through the CRM systems, relations are being harmonized not only with 
customers, but also with employees who are called upon to achieve their goals and comply with the required standards.

- maintaining a dialogue with customers, i.e., building long-term relationships in which customer loyalty is formed.

- setting realistic goals and evaluating performance. The CRM makes it possible to quickly monitor consumers' perception of various elements of the offer and elements that are important for each individual buyer and to correct them in a timely manner if necessary.

- relationship-based interfaces. The CRM implements the principle of flexibility and operability of communication with both internal and external clients.

Thus, this provides the basis for changing the business paradigm: development at the technological level (integration of applications, services, new niche CRM solutions, etc.) is complemented by changes at the organizational level. Now it has become important not only to collect information about your customers at all stages of the customer life cycle (attraction, retention, loyalty) and extract knowledge from it - an information and analytical circuit using advanced information technologies, but also to use this knowledge in the interests of business by building mutually beneficial relationships with them - a management circuit with a flexible business model. This formed the impetus for presenting the CRM as a concept aimed at building a sustainable business and then a business strategy, the core of which is a "customer-oriented" approach.

During this period, an attempt is made to summarize the accumulated practical experience and develop the basic principles of customer relationship management. It is noted that at that time, the study of the best practices of corporations did not reveal one company that would have succeeded in all aspects of the CRM. At the same time, examples of one or two specific best CRM practices in individual companies were found (Gordon 2002), which served as the basis for further typologization of the CRM [6].

But, despite the popularity of such systems, there is still no universal definition of the concept of the "CRM-system", and in the modern economy this term has been used in two meanings. First, as a designation for software that allows you to collect, store and work with customer information, keep records of communications, and analyze customer data [14]. However, this is true only if we talk about the CRM system in technological terms, that is, as a means of software support for management decisions of a certain class. As N. Siu rightly notes in his work, the term "CRM" itself has become much broader: "CRM is an interactive process aimed at achieving an optimal balance between corporate investment and customer satisfaction" [15]. Secondly, as a business concept aimed at creating a knowledge base about customers, focused on creating an effective mechanism for interacting with customers, in which one of the main strategic goals of the company becomes customer satisfaction. In our opinion, this approach is the most correct from the point of view of defining the concept of the "CRM", since it is the strategic tasks of the business that determine the need for software functionality focused on their support.

The classic functionality that is part of almost any CRM system includes, but is not limited to, a set of the following blocks [16], [17]:

- building and maintaining a customer base;

- record all customer contacts;

- customer classification;

- standardization of employee actions when interacting with customers;

- tracking the completion of tasks by each employee;

- subsystem of data exchange between employees;

- capture and store data about competitors.

However, given the transformation of the CRM itself as a business philosophy, such systems often include modules such as sales analysis and forecasting, planning and analyzing marketing campaigns, evaluating customer satisfaction, and even automating business processes. This has led to the fact that there are a large number of offers of information CRM systems on the market today, which differ in their intended purpose and functionality. The most common classification is based on the levels of information processing, which are solved by companies during the use of the CRM, in which they are divided into the following groups: informational (operational), analytical, strategic and mixed (collaborative) types [18], [6]. At the same time, it seems appropriate to systematize the functionality most often implemented in systems of this class at the present stage within the framework of the generally accepted classification (Table 1.).

At the same time, the variety of additional functions of such systems, even from the same manufacturers, makes it advisable to classify them by functionality: IP-telephony, SMS/E-mail mailing service, messenger, MS Excel, Reporting and accounting, ERP functionality, HRM functionality, ECM functionality [19]. At the same time, modern CRM systems can combine the components of other information systems or the functionality of other software.

Currently, the focus of research is again shifting slightly to applied research and detailed analysis of individual practices and specific cases of companies (groups of companies) on the features, opportunities, limitations and risks of implementing the CRM at various levels.

Thus, in the work of Feizi, an attempt was made to evaluate the management of customer relations with 
the performance of Internet services, the effectiveness of support and the effectiveness of marketing [20]. That is, not only the connections and the impact of the CRM on individual processes and indicators of the company are identified, but they are also evaluated for efficiency, the degree of elasticity.

There are studies of the secondary effects of the CRM implementation, which are regional in nature and are superimposed on cultural characteristics. In particular, the Ghazian article analyzes the social aspects of the CRM, which are associated with the expansion of customer opportunities, which in turn affects the growth of customer satisfaction. The importance of managing social relations to meet the needs of clients is emphasized, especially in light of the role of the intermediary in empowering clients in the Arab financial environment [21].

The narrow-applied research includes an attempt to develop a model that links the quality of the CRM and the quality of service with customer loyalty through their satisfaction [22].

Table 1. Types of CRM systems and their functionality

\begin{tabular}{|c|c|c|}
\hline $\begin{array}{l}\text { Type of } \\
\text { CRM- } \\
\text { system } \\
{[18]}\end{array}$ & Essence of CRM-system [6] & $\begin{array}{l}\text { Functional capabilities of CRM-system } \\
\text { (compiled by authors) }\end{array}$ \\
\hline 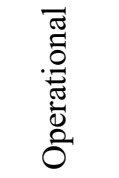 & $\begin{array}{l}\text { The main task of operational CRM } \\
\text { systems is to increase customer } \\
\text { loyalty in the process of direct } \\
\text { contact with them }\end{array}$ & $\begin{array}{l}\text { - accounting of all requests (registration of calls, emails, requests } \\
\text { to the site); } \\
\text { - storing data about clients, requests, transactions, and tasks in the } \\
\text { database }\end{array}$ \\
\hline 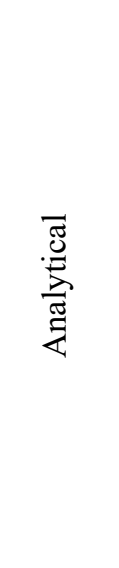 & $\begin{array}{l}\text { The goal of analytical CRM is to } \\
\text { analyze the accumulated } \\
\text { information about customers and } \\
\text { sales to build a more effective } \\
\text { strategy }\end{array}$ & $\begin{array}{l}\text { - automation of document flow within the company; } \\
\text { - tracking the progress of transactions in the sales funnel; } \\
\text { - reminder of scheduled calls, emails, meetings; } \\
\text { - setting tasks; } \\
\text { monitoring the work of employees } \\
\text {-dividing the customer base by parameters; } \\
\text { - determining the value of the client; } \\
\text { - analysis of customer profitability; } \\
\text { - analysis of marketing effectiveness; } \\
\text { - analysis of sales dynamics } \\
\text { - collecting feedback; } \\
\text { - attracting customers to product testing; } \\
\text { - analysis of reviews and suggestions; } \\
\text { - improving the service and product }\end{array}$ \\
\hline 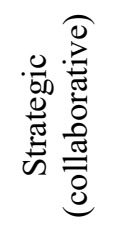 & $\begin{array}{l}\text { Strategic systems are based on } \\
\text { integration with other services and } \\
\text { interactive interaction with the } \\
\text { client. }\end{array}$ & $\begin{array}{l}\text { - collecting feedback; } \\
\text { - attracting customers to testing the product; } \\
\text { - analysis of reviews and suggestions; } \\
\text { - service and product improvement }\end{array}$ \\
\hline 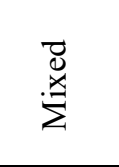 & $\begin{array}{l}\text { Useful CRM, but only suitable for } \\
\text { solving specific, narrow goals }\end{array}$ & $\begin{array}{l}\text {-analytical functions (reports on sales, customers, managers' } \\
\text { performance, etc.) } \\
\text { - communication with customers (thanks to integration with the } \\
\text { site, messengers, social networks) networks, etc.) }\end{array}$ \\
\hline
\end{tabular}

Source: calculated by the authors.

Hypothesis 1 (H1): The introduction of the CRM

This may be due to a new round of development of the CRM concept: we are talking not only about relationships with customers, but also with the entire external environment (suppliers, contractors, etc.) managing all business relationships. At the same time, such best practices are only being identified and there are still not enough data to fully systematize them.

Thus, the following research hypotheses can be determined: systems increases the efficiency of small business entities.

Hypothesis 2 (H2): The digital maturity of small business entities in Russia has reached a level that forms the demand for multifunctional versions of the CRM systems.

Hypothesis 3 (H3): There is a specific set of functional capabilities in the CRM system that are in demand from small businesses in Russia at the present stage, regardless of industry affiliation. 


\section{Materials and Methods}

\subsection{General Methods}

The main general scientific methods used in the work were: the method of analysis, synthesis, historical and chronological method, induction, deduction, content analysis of the semantic content of materials and articles on the development and functioning of CRM systems, which allowed combining individual results and moving hypotheses for empirical research.

\subsection{Specific Methods}

A comparative analysis of research on the CRM systems for small businesses in different countries allowed us to identify the evolution of general and specific features of the introduction of the CRM systems for small businesses.

The methods of descriptive statistics made it possible to conduct analytical processing of survey data and verify the hypotheses put forward. To process the respondents' responses, the functionality of the IBM SPSS Statistics 22 program was used to analyze distribution tables for each of the final thematic blocks and build cross-distributions.

\subsection{Forming a Questionnaire and Building a Sample}

The key thematic areas of the study, which formed the basis for the formation of the questionnaire questions, were identified based on the consideration of foreign sociological surveys revealing the features of the introduction of CRM systems in Egypt [23], Malaysia [24], the Czech Republic [25], Italy [26], as well as the results of the analysis of the main trends in the development of modern CRM systems. This conceptual and theoretical information acted as a methodological basis and the production of instrumental information - the formation of the basic part of the questionnaire.

Key survey topics (basic blocks):

- level of CRM system implementation;

- surveys on the use of the CRM system and its functionality, including the awareness of respondents in this area;

- criteria for selecting a CRM system;

- reasons preventing the implementation of CRM systems in small and medium-sized businesses;

- questions about the characteristics of the business (industry, region, etc.)

Nevertheless, the authors of this study focused more closely on the additional characteristics of the CRM market and the features of their implementation by small business representatives. In this regard, the basic questionnaire was expanded to:
- the list of answers about the main criteria for choosing a CRM system by small business representatives was significantly expanded;

- updated options for data collection and processing;

- added a block of questions about preferences in choosing a CRM system developer company;

- added a block of questions about the demand for various functionality of CRM systems.

The questionnaire included 26 key closed-type questions, taking into account the differentiation into the following final thematic blocks: methods of collecting and processing customer data in the activities of small businesses; readiness to implement CRM systems; perception of the effectiveness of implementing the CRM systems; reasons for choosing a CRM system; criteria for choosing a CRM system and the level of their use; preferred type of CRM systems; the most popular functionality in a CRM system; reasons for refusing to implement / delay the implementation of CRM systems; data about the company (respondent); respondents' comments on the subject of the study (Table 2.). Most of the questions were scalable. To increase the sensitivity of the indicators, nonparametric sociometry was used, in which, for a number of questions, respondents were not limited in the number of choices they made.

The respondents of the study were representatives of Russian small businesses companies whose average annual number of employees is up to 100 people, the maximum revenue from the sale of goods and services without VAT is up to 800 million rubles, which are included in the Unified Register of Small and Medium-Sized Businesses [27].

The recruitment of respondents took place in the following ways:

- an online newsletter with an invitation to participate in the survey to the representatives of small and medium-sized businesses, randomly generated by the authors on the basis of data from the "For Honest Business" system;

- independent recruitment of random people on the site of the social network Instagram;

- independent recruitment of random people (publication of links to the survey on third-party resources).

In total, more than 500 invitations were sent to representatives of small businesses in various industries and regions. As a result, 50 fully completed questionnaires were received by owners/managers of organizations in the small business segment of Russia. Thus, the response was quite low and amounted to about $10 \%$. The study was conducted in late 2020-early 2021 through an open information collection service - Google Forms. 


\section{Results}

\subsection{The Main Trends in the Development of Modern CRM Systems}

Information CRM systems are designed to support these practices by collecting and analyzing information from customers through various channels and points of contact between the client and the company, such as a website, telephone, chat, email and SMS mailing lists, advertising materials and social media.

According to the data rbc.pro, one of the key market trends is the increase in BMP solutions [14]. The BMP

combines a system for managing documentation and resources, tools for displaying simulated business processes, and modules for creating an IT infrastructure and integrating it with the company's business processes. For each business process, the company prescribes a strategy. And it is no longer the employee who chooses how to interact with a particular client - the system, in accordance with the strategy, gives him a particular task and sets a deadline for its completion. The potential for merging the functionality of a CRM system and a BMP system is great.

Moreover, three basic trends should be noted as the main recent trends in the development of these systems.

First, the popularity of cloud-based CRM services. However, this trend is more likely to be attributed to the general features of the development of information technologies at the present stage, than, in fact, to the specifics of the CRM systems as such.

Table 2. Methodological plan of a sociological survey of small business representatives on the features of implementing CRM systems (logical structure of methodological tools)

Thematic direction of the study

Questions

Testing the Descriptive Hypothesis 1 (H1)

The introduction of CRM systems increases the efficiency of small business entities

Methods of collecting and processing

customer data in the doer - news of

How do you collect and process customer data? (Q1.1)

small business representatives

Perception of the effectiveness of the Has the situation changed in your company after the introduction of

implementation of CRM systems

CRM? (Q1.2)

Testing the Hypothesis 2 (H2)

Explaining the digital maturity of small businesses in Russia has reached a level that forms the demand for multifunctional versions of CRM systems

Readiness to implement CRM systems The level of implementation of CRM systems in your company (Q2. 1)

Reasons for choosing a CRM system Highlight the main reasons for implementing CRM (Q2.2)

Testing the explanatory Hypothesis 3 (H3)

There is a specific set of functionalities in the CRM system that is in demand from small businesses in Russia at the present stage, regardless of industry affiliation

Criteria for choosing CRM systems

and the level of their use

Preferred type of CRM systems

The most popular functionality in the CRM system

Reasons for refusing to implement / delay the implementation of CRM systems

The main characteristics of the objects of research (representatives of small businesses)

Company Information

Respondents ' comments on the subject of the study

The main criteria for choosing a CRM (Q3.1)

Which CRM is implemented in the company (Q3.2)

Which CRM system developer company do you prefer (Q3.3)

What functionality do you most often use in CRM (Q3.4) What functionality of the CRM system is most important to you (Q3.5) Does your CRM system provide a feedback function to identify the client's expectations for business development (Q3.6)

How fully do you think CRM is used in your company? (Q3.7) Do you know/have heard/have an idea about the mobile version of CRM? (Q3.8) Are you going to use the mobile version of CRM? (Q3.9)

Barriers to CRM implementation (Q3.10)

Fill in the general information about the company: region (P1), industry (P2)

Additional information that you would like to provide for research (P3)

Source: calculated by the authors. 
Secondly, the emergence of independent applications of CRM systems that allow employees and consumers to use mobile communication tools.

For many companies, it is the mobile version that becomes the main one [28].

Third, the emergence of "social" CRM (SCRM), which some researchers already refer to a separate class of information systems. Social Customer Relationship Management (SCRM) is a new philosophy that influences the relationship between the customer and the organization, where the customer gets the opportunity to control the relationship with the manufacturer or company through social networks [29]. Van Looy [30] describes the SCRM as "an interdisciplinary approach to social media, since it involves all departments of the organization. Instead of connecting with people only with sales offers, the goal of the social CRM is to build strong relationships with Internet users by providing them with a positive experience with the organization's brand, products, and services."

Thus, the CRM today is a term for the practices, strategies, and technologies that a company uses to manage and analyze customer interactions, customer life cycles, in order to improve business relationships, retain customers, and increase sales [31].

\subsection{Comparative Analysis of Research on the CRM Systems for Small Businesses}

In general, the problem of promoting CRM systems for small businesses in the European Union is very relevant. Small enterprises in the European Union make up $98.84 \%$ of the total number of enterprises, which is why the European Commission often calls them "hidden giants". They are considered as the main factor of economic development. Currently, in the European Union, small enterprises in the non-financial business sector account for almost $67 \%$ of the employed workforce and generate $58 \%$ of the value added generated by the nonfinancial business sector [32].

Regarding the functionality demanded by small businesses, there is a sufficient amount of research conducted within specific countries. Conducting a cross-country study seems to many authors not entirely correct due to the different levels of development of informatization in the framework of a particular state, but their results are of undoubted interest.

Olof Wahlberg's work, "Trends, topics and underresearched areas in CRM research-a literature review" was among the first studies to emphasize that there is an obvious need for research on the CRM practices, including the implementation of the
CRM approach in the context of small businesses and in small organizations in general [18]. However, the first systematic country studies of the CRM implementation practices appeared somewhat later.

The most interesting and empirical works include the 2013 study, Hatem El-Gohary, David J. Edwards, and Juanling Huang Customer Relationship Management (CRM) Practices by Small Businesses in Developing Economies: A Case Study of Egypt" [23]. In order to test the proposed research hypotheses, a survey was conducted. The survey questionnaire focused on a sample of 504 small businesses. According to the results of the survey, 56 responses were received, where the majority of organizations $(82.1 \%)$ were located in Cairo. The results of the study show that for Egyptians, the most important factors influencing the introduction of the CRM in small businesses among internal factors are the skills of the owner and the size of the organization, the cost of implementing the CRM, among external factors-market trends and industry pressure.

Boon Kiat Loh, Khai Lun Koo, Kee Fai Ho, Rosnah Idrus from the Scientific University of Malaysia presented to the scientific community the publication "A Review of Customer Relationship Management System Benefits and Implementation in Small and Medium Enterprises", which highlighted the nuances associated with the implementation of CRM systems in the SMEs. However, this work mainly focuses on the study of the reasons why SMEs do not implement a CRM system [24]. The article is rather a review, which examines and analyzes the existing related works on the abovementioned aspects. The main reasons for the refusal are:

- many do not understand CRM technologies and do not know how to implement a particular CRM approach cost-effectively;

- in small enterprises, mostly owners and employees have limited technical knowledge or experience when it comes to implementing new technologies in the organization.

According to a survey of small enterprises on factors that influence the decision to implement the CRM conducted in the Czech Republic, including representatives of the global business, in 2018, the most significant criteria were recognized as CRM reliability $(81 \%)$, user-friendliness $(68 \%)$, support and service (58\%), compatibility with other IS in the enterprise (37\%) and price (35\%). Among the reasons why small enterprises did not implement the CRM were [25]:

- insufficient information;

- insufficient technical equipment; 
- low cost-effectiveness of the CRM to implement and use that these companies consider superior to their business.

The results of another study conducted by Italian scientists [26], which investigated the demand for digital technologies used by small enterprises, are very interesting. The authors divided these tools into 3 groups: search engine optimization tools, marketing tools, and interaction tools (Figure 1.).

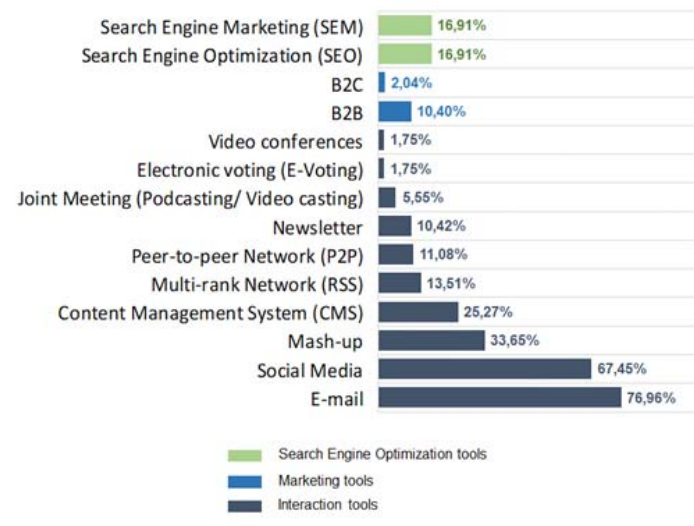

Figure 1. Percentage of digital technology adoption supporting small enterprises [26]

As the results of the study showed, in terms of interaction tools, it turned out that the SMEs usually use traditional digital technologies (such as e-mail and social media). As for marketing tools, in this case, small enterprises usually do not use more updated tools (for example, direct mail marketing, banner advertising, affiliate marketing, advertising games). Regarding search engine optimization tools, a significant proportion of the small enterprises participating in the study used SEO and SEM. The study highlights that the surveyed small enterprises used traditional technologies more intensively than innovative digital technologies, despite the fact that the latter are usually cheaper, more user-friendly and more efficient. The authors explain this by the fact that the majority of small enterprises do not have dedicated resources to monitor the development of the digital market and are not able to monitor technological dynamics, and these aspects force them to remain in a backward position. The researchers note that the survey mainly affected the "creative" (tourism, jewelry, handicraft production and trade) industries.

Studies on the topic of the CRM systems in the segment of small enterprises in Russia as such were not conducted, since it was believed that the Russian market of CRM systems for small businesses had not yet formed. At the same time, the authors of this article believe that it was in 2020 that significant changes occurred that could dramatically affect the situation in this segment.
First, the events of 2020 related to the pandemic created a situation in which the manufacturer of a product or service was deprived of the opportunity to actively interact with customers, which prompted many companies to think about the active implementation of CRM systems.

Secondly, the Russian market has a fairly large number of niche players offering relatively inexpensive CRM products for specific tasks (working with social networks, searching for tenders, booking, etc.) or for specific industries [2], [33].

It was these factors that led to the research interest of the authors, which prompted a survey among small businesses to determine the stage of implementation and readiness to use CRM systems, as well as to identify the factors that small companies take into account when deciding on the implementation of the CRM and the reasons why the CRM is not implemented in the company.

As can be seen from the research review presented above, similar surveys have been conducted in other countries before. The authors were interested in comparing the results, so the questionnaire included overlapping questions from the research data concerning the stages of system implementation, the specifics of collecting and processing customer data, the main reasons for implementing the CRM, and the criteria for choosing the CRM. However, the authors of this study focused more closely on such aspects as: the main criteria for choosing, significantly expanding the proposed list of answers, clarifying the options for data collection and processing, adding a block of questions about the preferences in choosing a developer company, as well as the demand for various functionality.

The choice of a particular CRM system solution is not limited to the choice of a supplier, which is only a separate step within the CRM system selection phase. Initially, it is necessary to determine the needs and requirements of the organization itself, which will allow you to create a complete list of business requirements and functional requirements for the CRM system. Based on this, you can build a separate CRM system configuration that corresponds to the business processes in the activities of small enterprises. Only then can you go to the supplier's selection.

Authors would like to note that in order to implement a CRM system in the organizational work of a company, it is not enough to simply focus on ratings and comparative tables of offers on the market. Everything is decided by the ability of the CRM system to be integrated into the business processes of a particular small enterprises. Therefore, you need to compare the specific work area (system requirements) and the technical capabilities of each CRM system from the potential software spectrum. 
Next, sales managers from vendor companies will come to the rescue, who will help you get acquainted with the functionality and provide a demo version for testing. In some cases, it will be necessary to involve external specialists-consultants to adjust the organization's business processes accordingly in order to maximize the benefits that the CRM system provides.

An important step after the launch of the CRM system at the stage of its deployment is the training of the employees. In addition to directly describing the functionality of the system, its capabilities and the reasons for implementation, the training also discusses the unclear functions and expectations of the SME management. The practice of real work, taking into account the use of the CRM system in solving current tasks, forms the involvement of employees and creates prerequisites for its daily and correct use in the activities of the SMEs.

\subsection{CRM Practices by Small Businesses in Russia}

\subsubsection{Methods of collecting and processing customer data in the activities of small businesses}

An analysis of existing practices on how to collect and process customer data showed that $80 \%$ of respondents collect and process customer data in some form. At the same time, $20 \%$ carry out the collection manually; $50 \%$ with the help of a comprehensive IT solution, $30 \%$ use a mixed form.

\subsubsection{Readiness for implementation}

According to the survey data, $54 \%$ of the 50 surveyed organizations in Russia have implemented a CRM system. $28 \%$ are considering or are in the process of implementing CRM systems. $18 \%$ do not plan to implement such systems. If we compare the results obtained with the study conducted in the Czech Republic, then, at first glance, we can note a large degree of implementation of such systems in Russia (Figure 2.).

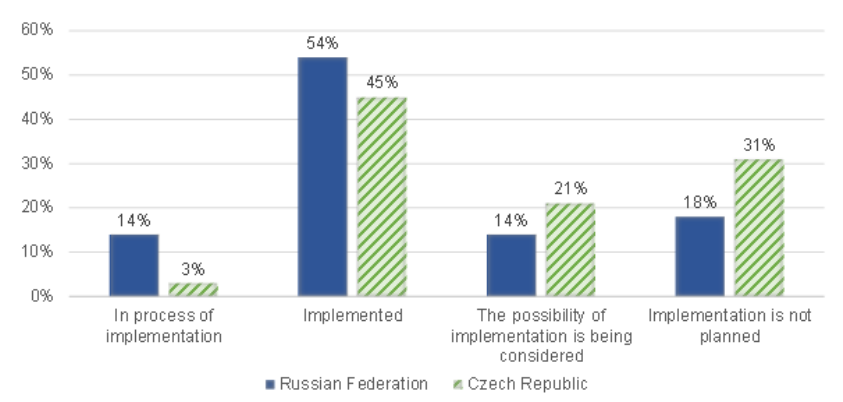

Figure 2. Comparison of the level of the CRM system implementation in companies in the Russian Federation (survey 2020-2021) and the Czech Republic (survey 2019)
However, such a conclusion seems premature to us, since the survey in the Czech Republic was conducted before the pandemic situation. Nevertheless, it is obvious that the representatives of small businesses in Russia are more positive about such systems and represent their benefits for their business. So, if in the Czech Republic 31\% of respondents categorically answered that the introduction of the CRM systems is not planned, then in Russia there were only $18 \%$ of such answers. There were no pronounced trends related to the type of activity of the company.

However, if we analyze the data obtained in more detail, taking into account the regional cross-section, we will get "mirror data", indicating that so far, mainly small businesses in Moscow and St. Petersburg are ready for informatization in this area: $76.6 \%$ of the surveyed companies in this region have implemented or are at the implementation stage. In the rest of Russia, only $55 \%$ of such companies are registered. Only $10 \%$ of respondents do not plan to implement it in federal cities, and $30 \%$ in other regions of the Russian Federation.

\subsubsection{Perception of the effectiveness of the implementation of CRM systems}

According to the survey data, those respondents who indicated the use of CRM systems in small business practice overwhelmingly $(88.9 \%)$ noted that the situation improved after the introduction of the CRM systems, and only $11.1 \%$ replied that there is no practice of evaluating the implementation result or the situation has worsened.

\subsubsection{Reasons for choosing a CRM system}

Respondents indicated "improving the efficiency of work processes and their transparency" as the main reason for the introduction of the CRM $(90.2 \%)$. The second most popular answer was "Improving sales performance" $(63,4 \%)$, and the choice of this option strongly depended on the industry affiliation of the company. It was chosen by those who are engaged in wholesale/retail trade or the provision of services. "Increasing customer loyalty and reducing customer churn" (29,3\%), as well as "reducing costs" $(24,4 \%)$ are at approximately the same level of importance for managers (Figure 3.). At the same time, it is most important, in comparison with the responses of other respondents who provide business services and are engaged in additional education. 


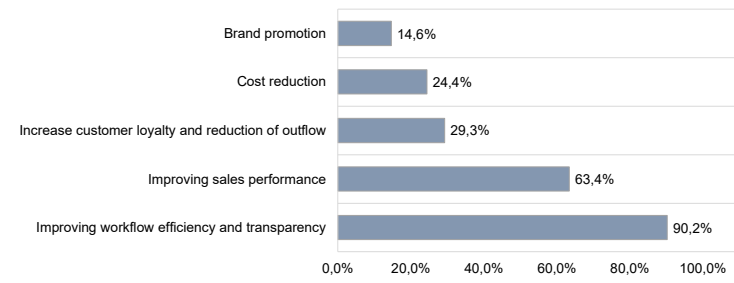

Figure 3. The main reasons for the introduction of CRM in the Russian Federation (multiple choice)

The study also showed that for respondents who are at the stage of implementing a CRM system, the main reason for the introduction was identified as "an increase in customer loyalty and a decrease in their outflow" (71.4\%), and "an increase in the efficiency of work processes and their transparency" (57.1\%) and "an increase in customer loyalty and a decrease in their outflow" (57.1\%) are additional factors. At the same time, it is also interesting to note that among the respondents who have already implemented CRM systems, the factor of "brand promotion" is practically not significant $(3.7 \%)$.

\subsubsection{Criteria for choosing a CRM system and the level of their use}

$100 \%$ of respondents who have implemented a CRM system consider the main criterion for choosing a CRM system to be "Ease of use for employees" (Figure 4.). The second most important criterion is "Product price" - this criterion was chosen by $52 \%$ of respondents. Moreover, to a greater extent, this criterion concerns companies in Moscow (61.1\%), regions $-33.3 \%$. Important criteria included in the TOP 5 are "System refinement with additional features and modules" and "Product conversion capability". The company's image and brand are not the key criteria when choosing a CRM system.

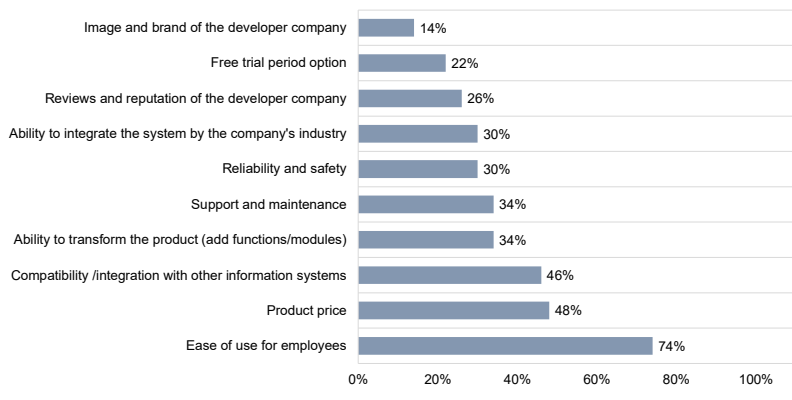

Figure 4. The main criteria for choosing a CRM in the Russian Federation (multiple choice)

It is interesting that the TOP 5 criteria for choosing a system between research in Russia and in the Czech Republic [25] differ radically in only one criterion: reliability is not the highest priority for Russian companies, while software development is not the main criteria for selection in the Czech Republic. The remaining criteria are weighty in the two studies being compared.

\subsubsection{Preferred type of CRM systems}

The majority of companies that have implemented a CRM system prefer the cloud type of software from a domestic manufacturer (52\%): Moscow - 61.11\% and $44.44 \%$ - other regions (Figure 5.).

Companies from the regions actively use Russian server solutions and their own developments. The implemented cloud type of software is a modern and practical solution for implementation in the organization. A huge plus of cloud systems is availability. The only drawback that all cloud technologies have is the need for technical means to access information: a computer connected to the Internet [28]. Cloud technologies reduce production costs and increase business efficiency [31].

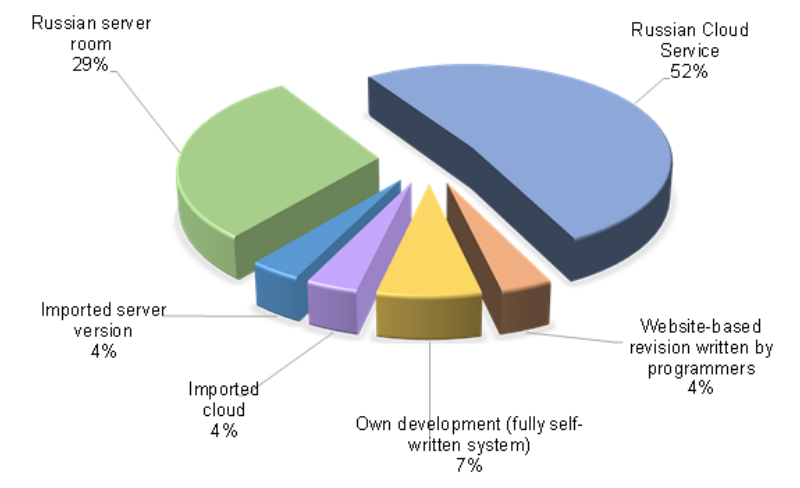

Figure 5. The type of implemented CRM in Russian companies

The most used products are Bitrix24 (26\%), amoCRM (15\%), and retailCRM (11\%). It should be especially noted that the share of individual developments remains quite high - $11 \%$. However, in this case, the respondents often had in mind the adaptation of the software based on the site. In this case, the preferences of companies from Moscow and other regions coincide.

The cloud type of software is the most preferred $(42.86 \%)$ compared to the server type of software $(28.57 \%)$ and for those companies that are just planning to implement it.

\subsubsection{The most popular functionality in the CRM system}

Respondents who have implemented a CRM system identified the most popular features in their CRM systems. It is important for the majority to be able to contact the client through various communication channels, generate reports and documents, keep the company's business processes under control, and integrate with the site - these functions were chosen by at least $50 \%$ of the respondents. Less popular are the functions of connecting an online sales register and the functions of accounting for the warehouse (Figure 6.). 


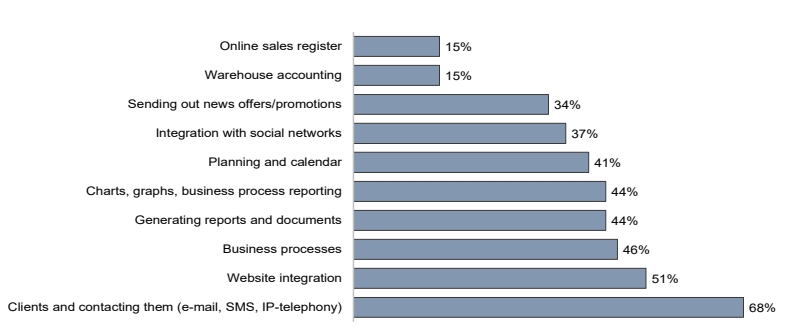

Figure 6. The most popular functionality in the CRM system

The analysis of the relationship between the level of implementation of the CRM systems and the functional capabilities most often used in the CRM systems showed that the importance of the ability to work with business processes is manifested only in respondents who have already implemented the CRM systems $(55.6 \%)$ or are at the stage of its implementation $(42.9 \%)$, while representatives of small businesses who are only considering the possibility of implementing a CRM system do not pay such attention to this functionality $(14.3 \%)$. The opposite situation is observed regarding the possibility of "integration with social networks" - it is not one of the main ones for respondents who have already implemented the CRM systems (25.9\%), while it is in the TOP 5 functional capabilities for representatives of small businesses who are at the stage of implementing a CRM system $(57.1 \%)$ or are just considering its implementation (57.1\%).

\subsubsection{Reasons for refusing to implement / delaying the implementation of CRM systems}

$18 \%$ of companies out of the total number of respondents who do not plan to implement CRM systems indicated that it is not economically feasible to implement a CRM system at this stage of their company's development (44.4\%). Equally, respondents assume $(22.2 \%)$ that they lack the technical capacity and knowledge about the functionality of the CRM systems.

Interestingly, the respondents of the Czech study [25] identified the same reasons why SMEs did not implement the CRM.

\section{Conclusions}

According to the results of the study, the following situation develops in the Russian segment of small businesses: most companies located in the central part of Russia, and especially in Moscow, actively use a CRM system to optimize the workflow of communication with the client, preferably a domestic developer. The Russian regions are lagging behind in terms of the level of the CRM system implementation compared to the capital, but a sufficient number of organizations are considering the possibility of implementation or are already in the process. There is a clear correlation between the demand for the functionality of the CSM systems, due to two factors, the catalyst for which was the conditions of the pandemic. Firstly, the need for remote interaction with clients brought to the fore the need for e-mail, SMS, IP telephony and other digital means and communication services. The main competitive advantage of a small business, which usually distinguishes it from business segments, is customer orientation. In the context of the pandemic, the usual channels of interaction for small businesses have become inaccessible (the restriction of face-toface contacts of the face-to-face type), which forced them to quickly look for alternative limited channels and digital forms of interaction.

Secondly, small businesses had to forcibly and rapidly reach a new level of digital maturity. To ensure this, it took a special knowledge of the inefficiency of existing business process management models and the formation of a system of knowledge about them in the organization. At the next stage of the development provoked by the pandemic, small businesses needed an unusual functionality for them- reporting on the effectiveness of business processes, taking into account visualization.

As the analysis showed, the introduction of the CRM systems within the framework of small businesses helped to level out failures in the efficiency of small business entities.

At the same time, the analysis of functional needs showed that the transition to the next level of digital maturity and the expansion of these needs will not happen in the near future.

Cloud-based CRM systems are a priority choice for companies. The company does not have a clear predominance of a certain brand of software due to the extensive and diverse offer of CRM systems from developers.

Thus, small businesses have formed a common specific set of requirements for the functionality of the CRM systems and for configuration types, regardless of industry affiliation.

\section{References}

[1]. Gartner.(2019). Gartner Says Worldwide Customer Experience and Relationship Management Software Market Grew $15.6 \%$ in 2018. Retrieved from: https://clc.am/Nu-GYg, [accessed@: 20 July 2021].

[2]. CRM: Russian market.(2020). TAdviser. Retrieved from: https://clc.am/0-vwoQ, [accessed: 23 July 2021].

[3]. Market Analysis Report. (2021). Customer Relationship Management Market Size, Share \& Trends Analysis Report By Solution (Customer Service, Customer Experience Management), By Deployment, By Enterprise Size, By End Use, And Segment Forecasts, 2021 - 2028. Retrieved from: https://clc.am/47asZw, [accessed: 23 July 2021]. 
[4]. Solodukha, P. V., Vasiutina, E. S., Korolkova, N. A., Erokhin, S. G., Starostenko, V. K., \& Matraeva, L. V. (2016). Structural contradiction of economic growth as a threat to the human capital reproduction process in Russia. International Journal of Economics and Financial Issues, 6(S1), 163-167.

[5]. Parasuraman, A., Zeithaml, V. A., \& Berry, L. L. (1985). A conceptual model of service quality and its implications for future research. Journal of Marketing, 49(4), 41-50.

[6]. Buttle, F. A. \& Maklan, S. (2006). Customer Relationship Management. Concepts and Tools. 3rd Edition. Publication place: Elsevier ButterworthHeinemann, p. 359.

[7]. Olsen, M. D., \& Connolly, D. J. (2000). Experiencebased travel: How technology is changing the hospitality industry. Cornell Hotel and Restaurant Administration Quarterly, 41(1), 30-40.

[8]. Gordon, I. (2002). Best practices: Customer relationship management. Ivey Business Journal, 67(2), 1-5.

[9]. Peel, J., \& Gancarz, M. (2002). CRM: redefining customer relationship management. Digital press.

[10]. Wilson, H., Daniel, E., \& McDonald, M. (2002). Factors for success in customer relationship management (CRM) systems. Journal of marketing management, 18(1-2), 193-219.

[11]. Jain, S. C. (2005). CRM shifts the paradigm. Journal of strategic marketing, 13(4), 275-291.

[12]. Sin, L.Y.M., Tse, A. \& Yim, F. H. (2005). CRM: conceptualization and scale development. European Journal of Marketing, 39(11/12), 1264-1290.

[13]. Osarenkhoe, A., \& Bennani, A. E. (2007). An exploratory study of implementation of customer relationship management strategy. Business Process Management Journal, 13(1), 139-164.

[14]. Five key trends of the CRM market in 2020. (2020). RKB Pro. Retrieved from: https://clc.am/FOdk g, [accessed: 26 July 2021].

[15]. Siu, N. Y. M. (2016). Customer Relationship Management and Recent Developments. Administrative Sciences, 6(3), 1-2.

[16]. Kinzyabulatov, R. (2019). What is a CRM program? Overview of CRM systems: what they are and how to use them effectively for small businesses. Technolakpiter.

[17]. Yurchenko, S. (2006). CRM is a tool for improving the efficiency of the enterprise. Problems of territory development, 34, 53-60.

[18]. Wahlberg, O., Strandberg, C., Sundberg, H., \& Sandberg, K. W. (2009). Trends, topics and underresearched areas in CRM research: a literature review. International Journal of Public information systems, 3, 191-208.

[19]. Matraeva, L., Korolkova, N. \& Dubs, A. (2020). Research of problems of development and implementation of CRM systems for small businesses in Russia. Economics and Management: problems, solutions, 8(104), 11-20.
[20]. Feizi, K. (2008). Customer Relationship Management and Customer Satisfaction : An Analysis Based on Quality of Service (Srkval) (Company E Corp), Improvement and Change Management Studies, 57, 105-132.

[21]. Ghazian, A., Hossaini, M. H., \& Farsijani, H. (2016). The effect of customer relationship management and its significant relationship by customers' reactions in LG Company. Procedia Economics and Finance, 36, 42-50.

[22]. Mokhtar, S., Mus, A. M., \& Sjahruddin, H. (2019). An examination of the relationships between customer relationship management quality, service quality, customer satisfaction and customer loyalty: The case of five star hotels. Advances in Social Sciences Research Journal, 6(2) 524-540.

[23]. El-Gohary, H., Edwards, D. J., \& Huang, J. (2013). Customer relationship management (CRM) practices by small businesses in developing economies: A case study of Egypt. International Journal of Customer Relationship Marketing and Management (IJCRMM), 4(2), 1-20.

[24]. Loh, B. K., Koo, K. L., Ho, K. F., \& Idrus, R. (2011, April). A review of customer relationship management system benefits and implementation in small and medium enterprises. In Proceedings of the 12th WSEAS international conference on Mathematics and computers in biology, business and acoustics (pp. 247-253).

[25]. Pohludka, M., \& Štverková, H. (2019). The best practice of CRM implementation for small-and medium-sized Sciences, 9(1), 22.

[26]. Castagna, F., Centobelli, P., Cerchione, R., Esposito, E., Oropallo, E., \& Passaro, R. (2020). Customer knowledge management in SMEs facing digital transformation. Sustainability, 12(9), 3899.

[27]. Federal tax service. (2020). Unified register of small and medium-sized businesses. Retrieved from: https://rmsp.nalog.ru/, [accessed: 10 August 2021].

[28]. Schiff, J.L. (2012). 8 CRM Trends You Need to Watch. CIO Magazine.

[29]. Kantorová, K., \& Bachmann, P. (2018). Social customer relationship management and organizational characteristics. Information, 9(12), 306.

[30]. Van Looy, A. (2005). Social customer relationship management. In Social Media Management. Technologies and Strategies for Creating Business Value. Publication place: Berlin, Heidelberg: Springer.

[31]. Rouse, M., Ehrens, T., \& Kiwak, K. (2019). CRM (customer relationship management). TechTarget.

[32]. European Commission. (2021). SME Performance Review. Retrieved from: https://clc.am/EXhwog, [accessed: 12 August 2021].

[33]. Institute of Business Problems. (2021). The Institute of Business Problems studied the CRM market in Russia. Retrieved from: https://clc.am/Q2KnJQ, [accessed: 15 August 2021]. 